\title{
A Community-Based Short Message Service Intervention to Improve Mothers' Feeding Practices for Obesity Prevention: Quasi-Experimental Study
}

Hong Jiang ${ }^{1,2^{*}}, \mathrm{PhD} ; \mathrm{Mu} \mathrm{Li}^{3,4^{*}}, \mathrm{PhD} ; \mathrm{Li}$ Ming Wen ${ }^{3,5}, \mathrm{PhD}$; Louise Baur ${ }^{3,6}, \mathrm{PhD}$; Gengsheng $\mathrm{He}^{1,2}, \mathrm{PhD}$; Xiaoying $\mathrm{Ma}^{1,2}, \mathrm{MS} ; \mathrm{Xu} \mathrm{Qian}^{1,2}, \mathrm{PhD}$

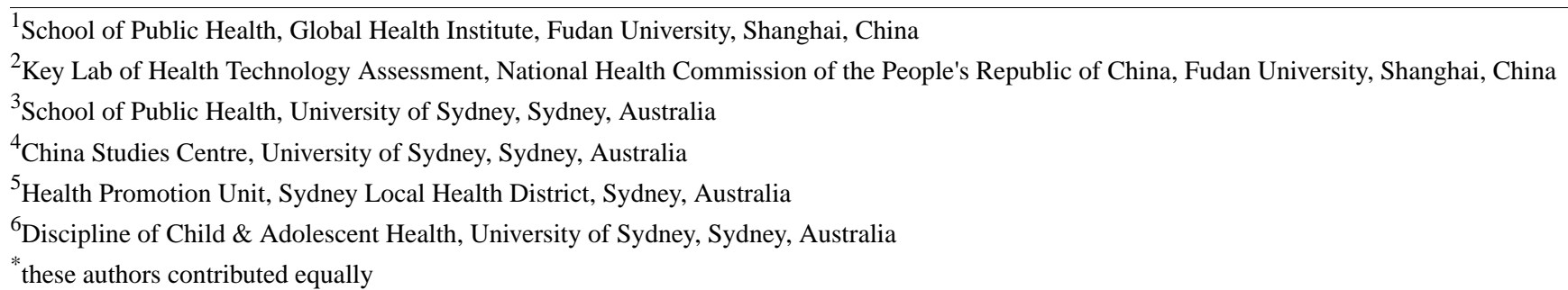

\section{Corresponding Author:}

Hong Jiang, PhD

School of Public Health

Global Health Institute

Fudan University

175 Mailbox

138 Yixueyuan Road

Shanghai, 200032

China

Phone: 862164179976

Fax: 862164179976

Email: $\underline{\text { h jiang@fudan.edu.cn }}$

\section{Related Article:}

This is a corrected version. See correction statement in: http://mhealth.jmir.org/2019/7/e15046/

\section{Abstract}

Background: The prevalence of childhood obesity is increasing in China, and the effect of mobile phone short message service (SMS) interventions to prevent early childhood obesity needs to be evaluated.

Objective: The objective of this study was to assess the effect of an SMS intervention on the prevention of obesity in young children.

Methods: A quasi-experimental design SMS intervention was carried out in 4 community health centers (CHCs) in Shanghai, China. A total of $2 \mathrm{CHCs}$ were assigned to the intervention group, and $2 \mathrm{CHCs}$ were assigned to the control group. Mothers in the intervention group received weekly SMS messages on breastfeeding and infant feeding from the third trimester to 12 months postpartum. The primary outcomes were children's body mass index (BMI), BMI z-score, and weight-for-length z-score at 12 and 24 months. Factors associated with higher BMI and weight-for-length z-score at 24 months were also assessed.

Results: A total of 582 expectant mothers were recruited at the beginning of the third gestational trimester. $477(82.0 \%)$ and $467(80.2 \%)$ mothers and their children were followed up to 12 and 24 months postpartum, respectively. There were no significant differences in children's BMI, BMI z-score, and weight-for-length z-score at 12 and 24 months between the 2 groups. Factors associated with higher BMI, BMI z-score, and weight-for-length z-score at 24 months included higher birth weight, introduction of solid foods before 4 months, and taking a bottle to bed at 12 months.

Conclusions: The SMS intervention did not show a significant effect on children's BMI, BMI z-score, or weight-for-length $\mathrm{z}$-score at 12 and 24 months. Introduction of solid foods before 4 months and taking a bottle to bed at 12 months were significantly and positively correlated with a higher BMI, BMI z-score, and weight-for-length z-score at 24 months. Further studies with more rigorous design are needed to evaluate the effect of SMS interventions on preventing early childhood obesity. 
(JMIR Mhealth Uhealth 2019;7(6):e13828) doi: 10.2196/13828

\section{KEYWORDS}

short message service; child development; body mass index; BMI; childhood obesity

\section{Introduction}

\section{Background}

Childhood obesity is a major public health concern globally. In China, the prevalence of obesity in children and adolescents aged 0 to 18 years increased from $0.4 \%$ in 1985 to $7.5 \%$ in 2010, a more than 18-fold increase in 25 years [1]. Early childhood, particularly the prenatal period, is a critical period to prevent obesity in later life $[2,3]$. There has been an increased interest in research on early childhood obesity interventions in recent years, including home- or caregiver-based interventions [4,5], interactive training modules for parents, and environmental change to promote healthy eating and active playing [6,7]. Such interventions have reportedly led to improvements in infant feeding practices (eg, increased duration of breastfeeding and a decrease in soft drink consumption) and a reduction in TV viewing while eating $[8,9]$. One study has also shown a reduction in body mass index (BMI) at age 24 months [8].

Mobile health (mHealth) refers to delivering health care and health promotion through mobile devices [10]. Mobile phone short message service (SMS) can deliver health care inexpensively through text messages wherever the person is located [11]. SMS text messaging has attracted global attention for its ability to enhance health care services [12,13]. Reported SMS text messaging in maternal and child health care are extensive, such as promoting prenatal care utilization, promoting exclusive breastfeeding, and improving the training of maternal and child health care providers $[10,11,14]$. The effects of these interventions, however, are underevaluated.

\begin{abstract}
Aims
We implemented an SMS intervention to first-time mothers in Shanghai, China. The overall aims of the study were to promote healthy infant feeding practices to new mothers and to examine whether the intervention is effective in preventing early onset of childhood obesity of their children. We have previously reported significant improvements in median exclusive breastfeeding (EBF) duration and rate of EBF at 6 months among the mothers receiving the intervention [15]. In this paper, we report the effect of this SMS intervention on the BMI, BMI z-score, and weight-for-length z-score of the children at 12 and 24 months. We also present factors associated with higher BMI, BMI z-score, and weight-for-length z-score at 24 months.
\end{abstract}

\section{Methods}

\section{Study Design}

This SMS text messaging intervention, using a quasi-experimental design, was conducted in Shanghai, China. A total of 4 community health centers (CHCs) were purposively selected from 2 administrative districts; 2 CHCs were assigned as the intervention group, and the other 2 were assigned to the control group. The intervention group received a weekly mobile phone SMS on appropriate infant feeding practices, plus routine child health care provided by CHCs. Participating mothers in the control group only received the routine child health care services. The intervention was carried out between December 2010 and October 2012. The 24-month anthropometric data collection was completed in October 2013. Written informed consent was obtained from each participant. Ethics approval was obtained from the Institutional Review Board of the School of Public Health, Fudan University, Shanghai, China, and the Human Research Ethics Committee of the University of Sydney, Sydney, Australia [15].

\section{Primary and Secondary Outcomes}

The primary outcomes of this intervention were child's BMI, BMI z-score, and weight-for-length z-score at 12 and 24 months. Length and weight data at 12 and 24 months were analyzed. Secondary outcomes were the proportion of infants introduced to solid foods before 4 months and taking a bottle to bed at 12 months; their associations with BMI at 24 months were also investigated.

\section{Participants and Recruitment}

The inclusion criteria and recruitment processes have been reported previously [15]. Essentially, eligible expectant mothers, owning a mobile phone, from the 4 communities were recruited to the study when they attended their first antenatal checkup in the CHCs after giving informed consent. They were asked to complete a baseline self-administered questionnaire, including questions on their initial awareness of the World Health Organization (WHO) breastfeeding guidelines [16]. CHC staff reviewed the participants' eligibility again at the beginning of the third trimester before the commencement of the SMS intervention.

\section{Sample Size}

To detect a difference in BMI of 0.4 units between the intervention and control groups at 24 months at the significance level of $P<.05$ with $80 \%$ power, a sample size of 446 (223 per arm) was needed. The estimation was made on the assumption of SDs of 1.4 and 1.6 for BMI at 24 months based on a published survey. Given an estimated loss to follow-up rate of $20 \%$ at the end of 24 months, 558 expectant mothers were required for the study.

\section{Short Message Service Intervention}

One weekly text message was sent to the participants in the intervention group from a computer-based platform from 28 weeks gestation to 12 months postpartum [15]. The total duration of the intervention was thus 66 weeks. Each text message contained approximately 180 to 210 characters. The messages were developed from the WHO breastfeeding guidelines and infant and young child feeding recommendations, in consultation with child health care experts and informed by a formative study [17]. The messages covered different stages of infant growth and development, providing anticipatory 
knowledge and guidance for appropriate infant feeding practices [15]. In addition, messages were sent periodically inquiring about the breastfeeding status, the time to return to work, or the timing of introducing semisolids or solids, so that appropriate messages could be sent in response to each woman's feeding situation. The control group received routine maternal and child health care in the CHCs. The control group received maternal and child health care routinely provided by the $\mathrm{CHCs}$, which included anthropometric measurements of length and weight periodically, responses to child feeding enquires, and assessment of the child development.

\section{Data Collection and Main Measurements}

Child health care doctors from the $4 \mathrm{CHCs}$ were trained for standard measurement and data collection procedures at the beginning of the study. The data on EBF, breastfeeding, and timing of introducing solids were collected and recorded by doctors via face-to-face interviews [15]. Child weight (to the nearest $0.1 \mathrm{~kg}$ ) and length (to the nearest $0.1 \mathrm{~cm}$ ) at 12 and 24 months were measured by the doctors using established methods and recorded using a standard protocol as part of a routine child health checkup [18]. Information on breastfeeding, timing of introducing semisolids and solids, and anthropometric measurement were extracted from the children's health records. Children's BMI at 12 and 24 months was calculated as weight in $\mathrm{kg} /(\text { length in } \mathrm{m})^{2}$, and BMI z-score and weight-for-length $\mathrm{z}$-score were calculated using the lambda-mu-sigma method based on the WHO Child Growth Standards [19]. At 12 months postpartum, a face-to-face interview was held with mothers by CHC staff in each CHC using a questionnaire adapted and translated from the Healthy Beginnings Trial [20]. Information on care givers' feeding practices, such as drinking from a cup, giving a bottle at bedtime, and using food for reward, was collected [15].

\section{Statistical Analysis}

Data quality control was performed before data analysis. The data were excluded if children's weight gain or length was less than $0.5 \mathrm{~kg}$ or $3 \mathrm{~cm}$ between birth weight and 12 months and between 12 and 24 months without any clinical indications.

Statistical analyses were made using the SPSS for Windows, version 17.0. Continuous variables were compared using independent samples $t$ test, proportions using the Pearson chi-squared test, and trends in proportions using Mantel-Haenszel chi-squared tests. Statistical significance level was set at $P<.05$.

Awareness of WHO breastfeeding guidelines was assessed with 6 questions in the baseline questionnaire. Each correct answer was scored 1 and an incorrect scored 0 . The total scores ranged from 0 to 6 , categorized into high or low score groups according to the median score.

BMI, BMI z-score, length, weight, and weight-for-length z-score at 12 and 24 months were analyzed as continuous variables. The effect of intervention on BMI, BMI z-score and weight-for-length $\mathrm{z}$-scores was determined by analysis of variance (ANOVA) after controlling for baby's birth weight; mothers' age, education level, preconception maternal BMI; household registration status, whether living in rental accommodation; and baseline awareness of WHO breastfeeding guidelines. The effect of the intervention on the child's BMI and BMI z-score was analyzed in the same way, with additional adjustment for baby's sex. As children might not be measured exactly when turning 12 or 24 months, further adjustment was made for the anthropometric data collection by exact child age (months to 2 decimal point). Similarly, the analysis of length and weight were further controlled for mother's preconception height and weight, respectively.

Multivariate linear regression was applied to analyze the factors associated with BMI, BMI z-score, and weight-for-length z-score at 24 months. Factors in the model included baby's birth weight; mothers' age and education level, awareness of the WHO breastfeeding guidelines at baseline, preconception BMI, EBF status at 6 months, breastfeeding duration (weeks), and introduction of solid foods before 4 months; care givers' feeding practices at 12 months, such as drinking from a cup, taking a bottle to bed, and using food for reward; and whether the family had Shanghai household registration and whether the family was living in a rental accommodation.

\section{Results}

\section{Recruitment and Follow-Up}

Of the 641 expectant mothers recruited from the 4 CHCs during their first visit, 582 were eligible at the beginning of the third trimester, 281 in the intervention group and 301 in the control group. There was no significant difference on main characteristics between women recruited in the first trimester and eligible in the third trimester. At 12 months, $82.0 \%$ (478/582) of the children's weight and length measurements were obtained, and $75.7 \%$ (441/582) of the mothers completed the questionnaire survey. At 24 months, 80.2\% (467/582) of the children's anthropometric data were collected (Figure 1).

\section{Participants' Main Characteristics}

Multimedia Appendix 1 shows the main characteristics of participants at baseline and at 12 and 24 months. At baseline, the mean age of the mothers was 28 years (range: $20-39$ years). $75.6 \%$ (440/582) of the mothers did not hold Shanghai household registration, and $86.4 \%(503 / 582)$ had tertiary education. Nearly one-half of mothers $(44.7 \%, 260 / 582)$ had a low awareness of WHO breastfeeding guidelines. Mothers who were lost to follow-up at 12 months were more likely to be living in a rental accommodation $(P<.001)$ and had a higher awareness score of WHO breastfeeding guidelines $(P=.02)$. Similarly, mothers who were lost to follow-up at 24 months were more likely to be living in a rental accommodation $(P<.001)$ and had a non-Shanghai household registration status $(P=.03)$. At 12 months, the average BMI of the children was $17.04 \mathrm{~kg} / \mathrm{m}^{2}$ (SE 0.06) ranging from 13.65 to 21.04 , and BMI $\mathrm{z}$-score was 0.46 (SE 0.04), with the range of -1.96 to 2.85 . At 24 months, the average BMI of the children was $15.92 \mathrm{~kg} / \mathrm{m}^{2}$ (SE 0.05) ranging from 12.62 to 20.22 , and the mean BMI z-score 0.05 (SE 0.04) ranging from -2.69 to 2.83 . 
Figure 1. Participant recruitment and retention. CHC: community health center; BMI: body mass index; HBV:hepatitis b virus.

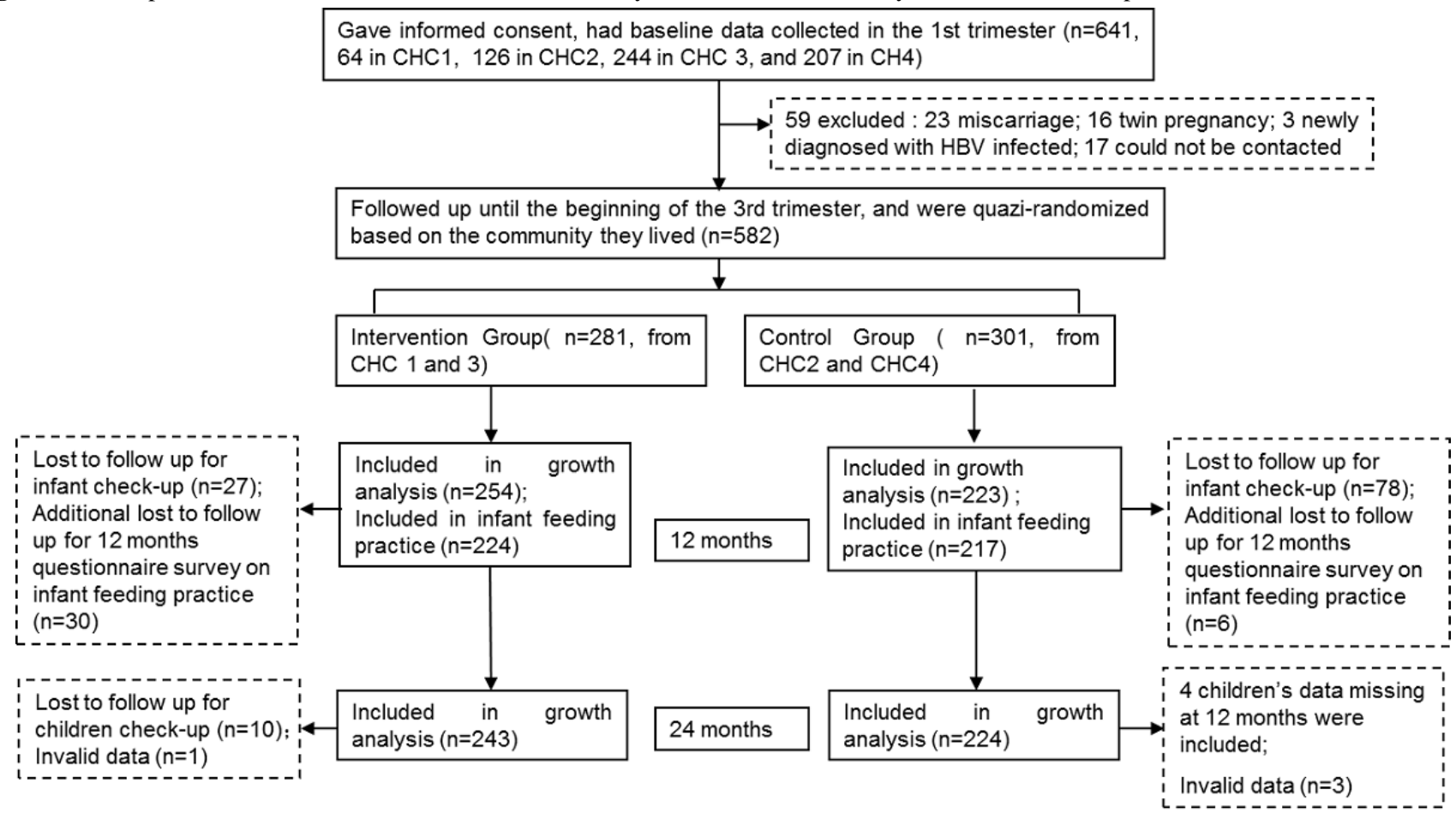

\section{Effect of the Intervention on Body Mass Index, Body} Mass Index Z-Score, and Weight-for-Length Z-Score

By ANOVA, there was no statistically significant difference between the intervention and control groups in BMI (mean $17.04 \mathrm{~kg} / \mathrm{m}^{2}$, SE 0.08 vs mean $17.04 \mathrm{~kg} / \mathrm{m}^{2}$, SE 0.08), BMI Z-score (mean 0.47, SE 0.05 vs mean 0.46, SE 0.06), or weight-for-length z-score (mean 0.44 , SE 0.05 vs mean 0.44 , SE 0.05) at 12 months. Similar results were found at 24 months for BMI (mean $15.93 \mathrm{~kg} / \mathrm{m}^{2}$, SE 0.07 vs mean $15.90 \mathrm{~kg} / \mathrm{m}^{2}$, SE 0.08), BMI z-score (mean 0.06, SE 0.06 vs mean 0.04, SE 0.06), or weight-for-length z-score (mean 0.44 , SE 0.05 vs mean 0.23 , SE 0.06), respectively (Multimedia Appendix 2). No difference was found in length and weight between children in intervention and control groups at 12 months and 24 months.

\section{Factors Associated With Body Mass Index and Body Mass Index Z-Score at 24 Months}

Table 1 shows the results of multiple linear regression analysis of factors associated with BMI, BMI z-score, and weight-for-length $\mathrm{z}$-score at 24 months. The factors significantly and positively correlated with BMI, BMI z-score, and weight-for-length $\mathrm{Z}$-score at 24 months included higher birthweight (all $P<.001$ ), introduction of solid foods before 4 months $(P=.003, P=.004$, and $P=.003$, respectively $)$, and taking a bottle to bed at 12 months $(P=.048, P=.044$, and $P=.036$, respectively). 
Table 1. Factors associated with body mass index (BMI) and BMI z-score at 24 months $(\mathrm{n}=359)$.

\begin{tabular}{|c|c|c|}
\hline Variables & $\operatorname{Beta}^{\mathrm{a}}(95 \% \mathrm{CI})$ & $P$ value $^{\mathrm{a}}$ \\
\hline \multicolumn{3}{|l|}{ BMI $^{b}$ at 24 months } \\
\hline Household registration & $-.144(-.416$ to .129$)$ & .30 \\
\hline Rental accommodation & $-.162(-.495$ to .172$)$ & .34 \\
\hline Awareness of $\mathrm{WHO}^{\mathrm{c}}$ breastfeeding guidelines at baseline & $.008(-.222$ to .248$)$ & .95 \\
\hline Maternal pre-pregnancy BMI & $.020(-.027$ to .067$)$ & .40 \\
\hline Maternal education & $.013(-.265$ to .291$)$ & .93 \\
\hline Birthweight & $.612(.343$ to .881$)$ & $<.001$ \\
\hline Baby's sex & $.113(-.121$ to .347$)$ & .34 \\
\hline Exact child's age at follow-up (month) & $-.139(-.378$ to .099$)$ & .25 \\
\hline Maternal age at recruitment & $-.045(-.252$ to .163$)$ & .67 \\
\hline $\mathrm{EBF}^{\mathrm{d}}$ at 6 months & $-.276(-.641$ to .090$)$ & .14 \\
\hline Introduction of solid foods before 4 month & $1.225(.429$ to 2.021$)$ & .003 \\
\hline Food used as a reward at 12 month & $.063(-.180$ to .307$)$ & .61 \\
\hline Drinking from a cup at 12 month & $-.101(-.341$ to .138$)$ & .41 \\
\hline Taking a bottle to bed at 12 month & $.239(.002$ to .477$)$ & .048 \\
\hline $\mathrm{BF}^{\mathrm{e}}$ duration (month) & $.001(-.031$ to .034$)$ & .94 \\
\hline \multicolumn{3}{|l|}{ BMI z-score at 24 months } \\
\hline Household registration & $-.110(-.319$ to .098$)$ & .30 \\
\hline Rental accommodation & $-.114(-.370$ to .142$)$ & .38 \\
\hline Awareness of WHO breastfeeding guidelines at baseline & $.010(-.173$ to .194$)$ & .91 \\
\hline Maternal pre-pregnancy BMI & $.010(-.026$ to .046$)$ & .58 \\
\hline Maternal education & $-.009(-.221$ to .203$)$ & .93 \\
\hline Birthweight & $.458(.252$ to .664$)$ & $<.001$ \\
\hline Maternal age at recruitment & $-.038(-.197$ to .121$)$ & .64 \\
\hline EBF at 6 months & $-.230(-.510$ to .050$)$ & .11 \\
\hline Introduction of solid foods before 4 month & $.888(.278$ to 1.498$)$ & .004 \\
\hline Food used as a reward at 12 month & $.033(-.153$ to .219$)$ & .73 \\
\hline Drinking from a cup at 12 month & $-.064(-.247$ to .120$)$ & .495 \\
\hline Taking a bottle to bed at 12 month & $.187(.005$ to .369$)$ & .04 \\
\hline BF duration (month) & $.003(-.022$ to .028$)$ & .80 \\
\hline \multicolumn{3}{|l|}{ Weight-for-length z-score at 24 months } \\
\hline Household registration & $-.113(-.312$ to .085$)$ & .26 \\
\hline Rental accommodation & $-.119(-.363$ to .124$)$ & .34 \\
\hline Awareness of WHO breastfeeding guidelines at baseline & $.012(-.163$ to .186$)$ & .90 \\
\hline Maternal pre-pregnancy BMI & $.010(-.024$ to .044$)$ & .56 \\
\hline Maternal education & $.004(-.198$ to .206$)$ & .97 \\
\hline Birthweight & $.518(.322$ to .714$)$ & $<.001$ \\
\hline Maternal age at recruitment & $-.029(-.181$ to .122$)$ & .70 \\
\hline EBF at 6 months & $-.241(-.507$ to .025$)$ & .08 \\
\hline Introduction of solid foods before 4 month & $.894(.313$ to 1.474$)$ & .003 \\
\hline Food used as a reward at 12 month & $.036(-.141$ to .213$)$ & 69 \\
\hline
\end{tabular}




\begin{tabular}{lll}
\hline Variables & Beta $^{\mathrm{a}}(95 \% \mathrm{CI})$ & $P$ value $^{\mathrm{a}}$ \\
\hline Drinking from a cup at 12 month & $-.057(-.231$ to .117$)$ & .52 \\
Taking a bottle to bed at 12 month & $.186(.013$ to .359$)$ & .04 \\
BF duration (month) & $-.002(-.026$ to .022$)$ & .86 \\
\hline
\end{tabular}

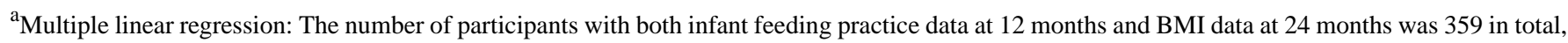
197 from the intervention group, and 162 from the control group.

${ }^{\mathrm{b}} \mathrm{BMI}$ : body mass index.

${ }^{\mathrm{c}}$ WHO: World Health Organization.

${ }^{\mathrm{d}}$ EBF: exclusive breastfeeding.

${ }^{\mathrm{e}} \mathrm{BF}$ : breastfeeding.

\section{Discussion}

\section{Principal Findings}

Our study found that the SMS intervention, delivered to mothers on a weekly basis from the third trimester until 12 months postpartum, had no significant effect on their children's BMI, BMI z-score, or weight-for-length z-score at 12 and 24 months. Higher birth weight, introduction of solid foods before 4 months, and taking a bottle to bed at 12 months were found significantly and positively associated with higher BMI, BMI z-score, and weight-for-length z-score at 24 months.

\section{Strength and Limitations}

The study was a quasi-experimental design, community-based intervention, with a high follow-up rate at 12 and 24 months. The SMS intervention was proven to be feasible and practical in improving breastfeeding practices, including significantly higher EBF rate at 6 months, longer median duration of EBF, and lower rate of instruction of solid foods before 4 months $[15,17]$. Although the intervention did not demonstrate significant effect on children's BMI or BMI z-score at 24 months, several infant feeding practices were identified as potentially important influencing factors. There are several limitations of the study. Participants were not randomized to the intervention and control groups, and some characteristics, for example, maternal age, education, and birth weight, were significantly different between the 2 groups. Therefore, multiple regression was used to control confounding factors. Moreover, although SMS intervention is seen to be low cost, and potentially suitable for low resource settings, the cost-effectiveness of SMS intervention was not explored in our study. Information on other possible risk factors of obesity at 24 months, such as physical activity levels and TV viewing time, were not collected.

\section{Interpretation of the Research Findings}

Among the published early childhood obesity prevention studies, the Healthy Beginnings Trial is the only study that showed a significant reduction in BMI $\left(0.38 \mathrm{~kg} / \mathrm{m}^{2}\right.$ mean decrease, $\left.P=.01\right)$ in children of the intervention group at 24 months [8,21]. This trial was a multicomponent intervention delivered through 8 home visits by trained community nurses [8]. The NOURISH trial, comprising 2 interactive group education modules, each delivering over 3 months to new mothers to promote healthy eating patterns, demonstrated a small but not statistically significant reduction in mean BMI z-score of $0.14(P=.12)$ [22].
Compared with these 2 studies, our intervention, with 1 weekly text message with no more than 210 characters, had much lower intensity. This could be one explanation for not showing effect on BMI z-score or the BMI. The results could also be due to a type 2 error-inadequate statistical power to detect the difference because there was a limited reference for postulating a meaningful expected difference for estimating sample size.

Whether early introduction of solid foods affects BMI in later childhood is still a contested topic. Some studies suggest that early introduction of solids is associated with increased childhood BMI [23], whereas others did not support such a conclusion [24,25]. We found that the introduction of solid foods before 4 months was positively associated with a higher BMI, BMI z-score, and weight-for-length z-score at 24 months. This finding is in keeping with previous reported studies [26,27]. No association between EBF or duration of breastfeeding with BMI, BMI z-score, and weight-for-length z-score at 24 months was found, which was consistent with 1 prospective study [28], but different to other studies' findings [26,29]. Further research is needed to confirm breastfeeding promotion as a robust childhood obesity prevention strategy [30].

Our study showed that giving an infant a bottle to take to bed at 12 months, which is a less reported practice, was positively associated with a higher BMI, BMI z-score, and weight-for-length $\mathrm{z}$-score at 24 months. However, we found no significant association between drinking from a cup at 12 months and anthropometric status at the age of 24 months. This is consistent with a randomized controlled trial that also failed to show an association between reduced bottle usage from 12 months and adiposity at 24 months [31]. However, links were found between bottle use at 24 months and higher obesity prevalence at the age of 5.5 years in an observational study [32].

\section{Future Research}

mHealth intervention as an effective strategy to promote breastfeeding and infant feeding and childhood obesity prevention still requires further research using stronger study designs and larger sample sizes. Research on motivations and barriers for mothers to adopt healthy child feeding behaviors is needed to inform the development of effective interventions. The cost-effectiveness of SMS interventions compared with facility-based interventions also needs to be determined. 


\section{Conclusions}

Overweight and obesity in children are affected by many factors. Although no significant effect of this SMS intervention on children's BMI, BMI z-score, or weight-for-length z-score at 12 and 24 months was found, we have identified several influencing factors. The introduction of solid foods before 4 months, taking a bottle to bed at 12 months, and high birth weight were significantly and positively correlated with a higher BMI, BMI z-score, and weight-for-length z-score at 24 months. Furthermore, large-scale randomized controlled trials are needed to evaluate the effectiveness and cost- effectiveness of SMS text messaging interventions on the prevention of early childhood obesity, including the usability, intensity, frequency, and duration of the interventions.

\section{Acknowledgments}

The authors thank all participants and staff in CHCs involved in the study. They also thank Qiaozhen Hu, Dongling Yang, and Yang Li for data collection during the research. This study was funded by the Nestle Foundation (Small Research Grant) and Shanghai Municipal Health Bureau (no.12GWZX0301 and no. 15GWZK0402).

\section{Authors' Contributions}

ML, XQ, and HJ conceptualized and designed the study. LMW, ML, XQ, GH, and HJ designed the data collection instruments. XQ and HJ coordinated and supervised data collection at 4 study sites. HJ carried out the initial analyses. HJ and ML drafted the initial manuscript, and LMW and LB provided critical comments on intellectual content. All authors reviewed and revised the manuscript and approved the final manuscript as submitted.

\section{Conflicts of Interest}

None declared.

\section{Multimedia Appendix 1}

Characteristics of mothers and babies in the study, Shanghai China 2010-13.

[DOCX File, 21KB-Multimedia Appendix 1]

\section{Multimedia Appendix 2}

Body mass index (BMI), BMI z-score and weight for length z-score $(\mathrm{kg} / \mathrm{m} 2)$ between children in the intervention and control groups at 12 and 24 months.

[DOCX File, 21KB-Multimedia Appendix 2]

\section{References}

1. Yu Z, Han S, Chu J, Xu Z, Zhu C, Guo X. Trends in overweight and obesity among children and adolescents in China from 1981 to 2010: a meta-analysis. PLoS One 2012;7(12):e51949 [FREE Full text] [doi: 10.1371/journal.pone.0051949] [Medline: 23284829]

2. Baird J, Fisher D, Lucas P, Kleijnen J, Roberts H, Law C. Being big or growing fast: systematic review of size and growth in infancy and later obesity. Br Med J 2005 Oct 22;331(7522):929 [FREE Full text] [doi: 10.1136/bmj.38586.411273.E0] [Medline: $\underline{16227306]}$

3. Glavin K, Roelants M, Strand BH, Júlíusson PB, Lie KK, Helseth S, et al. Important periods of weight development in childhood: a population-based longitudinal study. BMC Public Health 2014 Feb 13;14:160 [FREE Full text] [doi: 10.1186/1471-2458-14-160] [Medline: 24524269]

4. Salvy S, de la Haye K, Galama T, Goran MI. Home visitation programs: an untapped opportunity for the delivery of early childhood obesity prevention. Obes Rev 2017 Dec;18(2):149-163 [FREE Full text] [doi: 10.1111/obr.12482] [Medline: 27911984]

5. Wen LM, Rissel C, Baur LA, Hayes AJ, Xu H, Whelan A, et al. A 3-arm randomised controlled trial of Communicating Healthy Beginnings Advice by Telephone (CHAT) to mothers with infants to prevent childhood obesity. BMC Public Health 2017 Dec 14;17(1):79 [FREE Full text] [doi: 10.1186/s12889-016-4005-x] [Medline: 28088203]

6. Campbell KJ, Hesketh KD, McNaughton SA, Ball K, McCallum Z, Lynch J, et al. The extended Infant Feeding, Activity and Nutrition Trial (InFANT Extend) Program: a cluster-randomized controlled trial of an early intervention to prevent childhood obesity. BMC Public Health 2016 Feb 18;16:166 [FREE Full text] [doi: 10.1186/s12889-016-2836-0] [Medline: 26888759]

7. Bean MK, Thornton LM, Jeffers AJ, Gow RW, Mazzeo SE. Impact of motivational interviewing on engagement in a parent-exclusive paediatric obesity intervention: randomized controlled trial of NOURISH+MI. Pediatr Obes 2018 Dec 4:e12484. [doi: 10.1111/ijpo.12484] [Medline: 30515995] 
8. Wen LM, Baur LA, Simpson JM, Rissel C, Wardle K, Flood VM. Effectiveness of home based early intervention on children's BMI at age 2: randomised controlled trial. Br Med J 2012;344:e3732 [FREE Full text] [doi: 10.1136/bmj.e3732] [Medline: 22735103]

9. Daniels LA, Mallan KM, Battistutta D, Nicholson JM, Meedeniya JE, Bayer JK, et al. Child eating behavior outcomes of an early feeding intervention to reduce risk indicators for child obesity: the NOURISH RCT. Obesity (Silver Spring) 2014 May;22(5):E104-E111 [FREE Full text] [doi: 10.1002/oby.20693] [Medline: 24415390]

10. Premji S. Mobile health in maternal and newborn care: fuzzy logic. Int J Environ Res Public Health 2014 Jun;11(6):6494-6503 [FREE Full text] [Medline: 25003177]

11. Krishna S, Boren SA, Balas EA. Healthcare via cell phones: a systematic review. Telemed J E Health 2009 Apr;15(3):231-240. [doi: 10.1089/tmj.2008.0099] [Medline: 19382860]

12. Fjeldsoe BS, Marshall AL, Miller YD. Behavior change interventions delivered by mobile telephone short-message service. Am J Prev Med 2009 Feb;36(2):165-173. [doi: 10.1016/j.amepre.2008.09.040] [Medline: 19135907]

13. McCartney P. Global maternal-child mobile health. MCN Am J Matern Child Nurs 2012 Sep;37(5):347. [doi: 10.1097/NMC.0b013e3182619089] [Medline: 22895209]

14. Stephens J, Allen J. Mobile phone interventions to increase physical activity and reduce weight: a systematic review. J Cardiovasc Nurs 2013;28(4):320-329 [FREE Full text] [doi: 10.1097/JCN.0b013e318250a3e7] [Medline: 22635061]

15. Jiang H, Li M, Wen LM, Hu Q, Yang D, He G, et al. Effect of short message service on infant feeding practice: findings from a community-based study in Shanghai, China. JAMA Pediatr 2014 May;168(5):471-478 [FREE Full text] [doi: 10.1001/jamapediatrics.2014.58] [Medline: 24639004]

16. Jiang H, Li M, Yang D, Wen LM, Hunter C, He G, et al. Awareness, intention, and needs regarding breastfeeding: findings from first-time mothers in Shanghai, China. Breastfeed Med 2012 Dec;7(6):526-534 [FREE Full text] [doi: 10.1089/bfm.2011.0124] [Medline: 22424469]

17. Jiang H, Li M, Wen LM, Baur LA, He G, Ma X, et al. A short message service intervention for improving infant feeding practices in Shanghai, China: planning, implementation, and process evaluation. JMIR Mhealth Uhealth 2018 Oct 29;6(10):e11039 [FREE Full text] [doi: 10.2196/11039] [Medline: 30373728]

18. Cogill B. Food and Nutrition Technical Assistance. Anthropometric Indicators Measurement Guide URL: https://www. fantaproject.org/sites/default/files/resources/anthropometry-2003-ENG.pdf [accessed 2019-05-14] [WebCite Cache ID 78MvIDHOF]

19. World Health Organization. Child growth standards URL: https://www.who.int/childgrowth/standards/bmi for age/en/ [accessed 2019-05-14] [WebCite Cache ID 78MvK3hdV]

20. Wen LM, Baur LA, Simpson JM, Rissel C, Flood VM. Effectiveness of an early intervention on infant feeding practices and. Arch Pediatr Adolesc Med 2011 Aug;165(8):701-707. [doi: 10.1001/archpediatrics.2011.115] [Medline: 21810633]

21. Wen LM, Baur LA, Simpson JM, Xu H, Hayes AJ, Hardy LL, et al. Sustainability of effects of an early childhood obesity prevention trial over time: a further 3-year follow-up of the Healthy Beginnings Trial. JAMA Pediatr 2015 Jun;169(6):543-551. [doi: 10.1001/jamapediatrics.2015.0258] [Medline: 25893283]

22. Daniels LA, Mallan KM, Nicholson JM, Battistutta D, Magarey A. Outcomes of an early feeding practices intervention to prevent childhood obesity. Pediatrics 2013 Jul;132(1):e109-e118. [doi: 10.1542/peds.2012-2882] [Medline: 23753098]

23. Huh SY, Rifas-Shiman SL, Taveras EM, Oken E, Gillman MW. Timing of solid food introduction and risk of obesity in preschool-aged children. Pediatrics 2011 Mar;127(3):e544-e551 [FREE Full text] [doi: 10.1542/peds.2010-0740] [Medline: 21300681]

24. Moorcroft KE, Marshall JL, McCormick FM. Association between timing of introducing solid foods and obesity in infancy and childhood: a systematic review. Matern Child Nutr 2011 Jan;7(1):3-26. [doi: 10.1111/j.1740-8709.2010.00284.x] [Medline: 21143583]

25. Symon B, Crichton GE, Muhlhausler B. Does the early introduction of solids promote obesity? Singapore Med J 2017 Nov;58(11):626-631 [FREE Full text] [doi: 10.11622/smedj.2017024] [Medline: 28367583]

26. Wen LM, Baur LA, Rissel C, Xu H, Simpson JM. Correlates of body mass index and overweight and obesity of children aged 2 years: findings from the healthy beginnings trial. Obesity (Silver Spring) 2014 Jul;22(7):1723-1730 [FREE Full text] [doi: 10.1002/oby.20700] [Medline: 24415528]

27. Kramer MS. Breastfeeding, complementary (solid) foods, and long-term risk of obesity. Am J Clin Nutr 2010 Mar;91(3):500-501. [doi: 10.3945/ajen.2010.29199] [Medline: 20107200]

28. Neutzling MB, Hallal PR, Araújo CL, Horta BL, Vieira MD, Menezes AM, et al. Infant feeding and obesity at 11 years: prospective birth cohort study. Int J Pediatr Obes 2009;4(3):143-149. [doi: 10.1080/17477160802453530] [Medline: 19353369]

29. Harder T, Bergmann R, Kallischnigg G, Plagemann A. Duration of breastfeeding and risk of overweight: a meta-analysis. Am J Epidemiol 2005 Sep 1;162(5):397-403. [doi: 10.1093/aje/kwi222] [Medline: 16076830]

30. Lumeng JC, Taveras EM, Birch L, Yanovski SZ. Prevention of obesity in infancy and early childhood: a National Institutes of Health workshop. JAMA Pediatr 2015 May;169(5):484-490. [doi: 10.1001/jamapediatrics.2014.3554] [Medline: 25775180]

31. Bonuck K, Avraham SB, Lo Y, Kahn R, Hyden C. Bottle-weaning intervention and toddler overweight. J Pediatr 2014 Feb;164(2):306-12.e1. [doi: 10.1016/j.jpeds.2013.09.029] [Medline: 24183206] 
32. Gooze RA, Anderson SE, Whitaker RC. Prolonged bottle use and obesity at 5.5 years of age in US children. J Pediatr 2011 Sep;159(3):431-436. [doi: 10.1016/j.jpeds.2011.02.037] [Medline: 21543085]

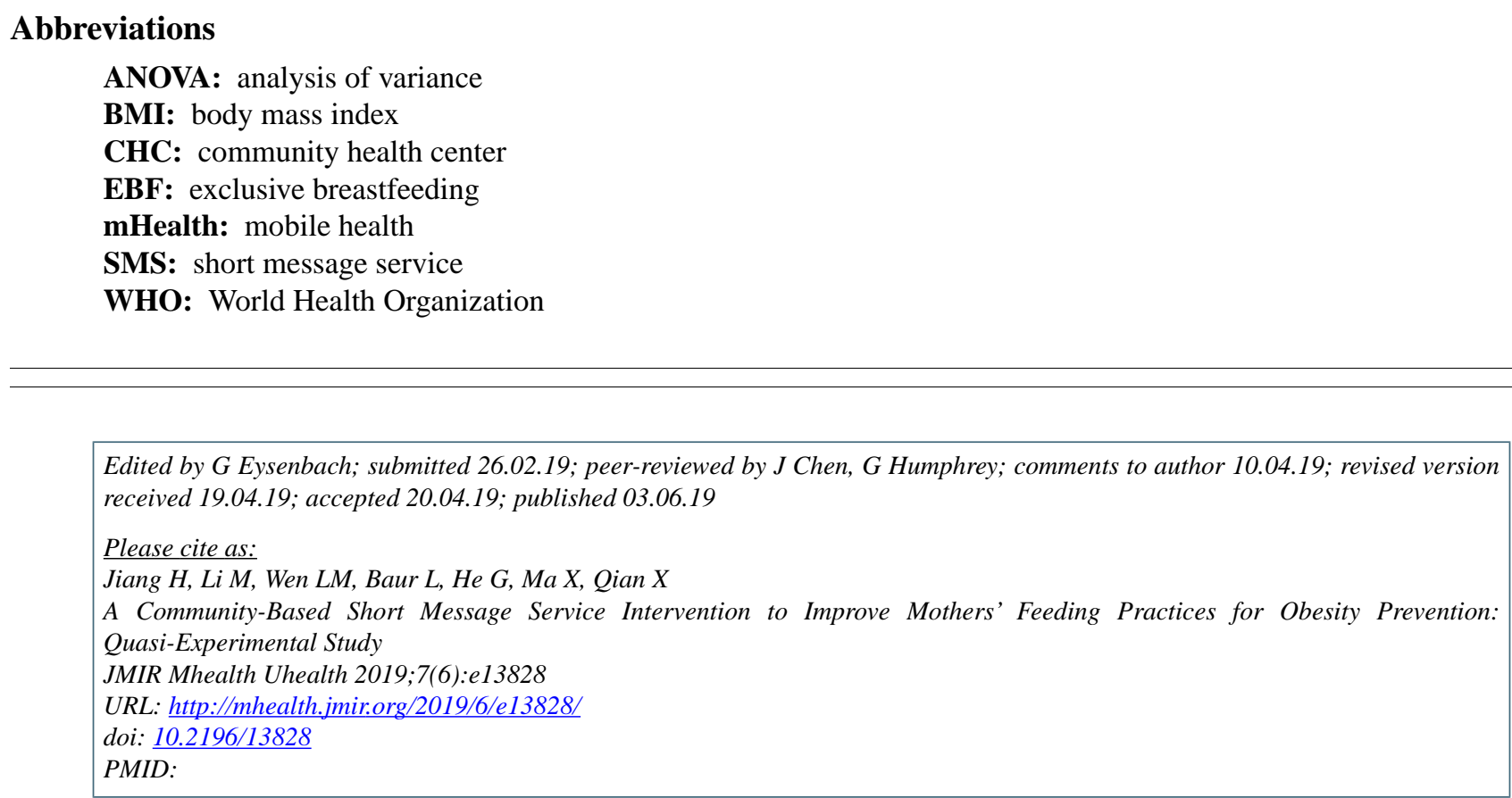

CHong Jiang, Mu Li, Li Ming Wen, Louise Baur, Gengsheng He, Xiaoying Ma, Xu Qian. Originally published in JMIR Mhealth and Uhealth (http://mhealth.jmir.org), 03.06.2019. This is an open-access article distributed under the terms of the Creative Commons Attribution License (https://creativecommons.org/licenses/by/4.0/), which permits unrestricted use, distribution, and reproduction in any medium, provided the original work, first published in JMIR mhealth and uhealth, is properly cited. The complete bibliographic information, a link to the original publication on http://mhealth.jmir.org/, as well as this copyright and license information must be included. 